\title{
What effect does participating in an assistance dog program have on the quality of life of children with Autism Spectrum Disorders and their caregivers? A systematic review of current literature
}

\author{
Esther Sprod \\ Occupational Therapist \\ Michael Francis Norwood \\ Griffith University
}

\begin{abstract}
The use of assistance dogs for children with Autism Spectrum Disorder is an emerging field, with interventions varying from formal assistance dog programs aimed at increasing child safety in public, to incorporating assistance dogs into therapy sessions. Previous reviews have suggested mostly positive outcomes from participating in such programs, however cited a lack of high quality studies available. This systematic review aims to answer the question: what effect does participating in an assistance dog program have on the quality of life of children with Autism Spectrum Disorders and their caregivers? After analysis, ten studies were deemed to meet the inclusion and exclusion criteria, and were included in the review. Findings suggest that participating in various Autism assistance dog programs can: 1) increase child safety in public, which in turn decreases self-reported parental stress and increases self-reported parental confidence in managing their child; 2) increase positive behaviours and decrease negative behaviours; and 3) facilitate motor, communication and social development. However, disparities were found between studies, particularly between quantitative and qualitative results, and between the quality of the projects' design. These factors indicate that further, high quality research is still needed to support emerging evidence.
\end{abstract}

Keywords: Animal-assisted intervention, animal-assisted therapy, Autism, children, assistance dog, quality of life, carer well-being, therapy dog

In 2012, $0.5 \%$ of the population in Australia was diagnosed as being on the Autism Spectrum (Australian Bureau of Statistics (ABS), 2012). This represents a sharp increase from 2009 (up $79 \%$ ), with the prevalence continuing to grow for unknown and contested reasons (ABS, 2012). Autism Spectrum Disorder (ASD) is characterised by persistent deficits in communication and social interaction, and restricted, repetitive behaviours, interests or activities (American Psychiatric Association, 2013). As a result, children with ASD can experience significant impairments in their overall development and functioning (Hall, Wright, \& Mills, 2016). Children with ASD often also experience challenging behaviours including frequent meltdowns, unsociable behaviours (such as hurting themselves or others, or selfstimulation through rocking or hand flapping), and frequent absconding in public (Raising Children Network, 2016). Because of these factors, compared to parents of typically developing children, parents of children with ASD report higher levels of stress and anxiety (Dunn, Burbine, Bowers, \& Tantleff-Dunn, 2001). Having a child with ASD can place significant

Corresponding author: Esther Sprod (esther.a.sprod@gmail.com) 
strain on the entire family unit due to the challenging behaviours often exhibited by children with ASD, as well the financial burden of therapies, neglected siblings, and social isolation caused by difficult behaviours in public and negative public opinion (Burrows, Adams, \& Spiers, 2008).

The use of assistance dogs for children with ASD is an emerging field, with interventions varying from formal assistance dog programs aimed at increasing child safety in public, to the use of therapy dogs as part of efforts to improve support for children with ASD and their families. There is a distinction to be made between an 'assistance dog' and a 'therapy dog'. Both fall under the broader category of 'animal assisted intervention' (O'Haire, 2013) however, one is activity based and another therapy based. Formal Autism assistance dog programs aim to increase the child's safety in public through a belt attachment around the child's waist connected to the dog's coat (Burrows et al., 2008); whereas with a therapy dog, a therapist is present and interactions take place alongside activities aiming to facilitate social behaviours and use of language (Berry, Borgi, Francia, Alleva, \& Cirulli, 2013). The term 'assistance dog' will be used to describe both therapy dogs and assistance dogs throughout this paper as the two have been considered together in previous reviews under the broader category of animal assisted therapy (Berry et al., 2013; O'Haire, 2012).

The use of assistance dogs for children with ASD began in Canada in 1997 and has grown around the world since then (Smyth \& Slevin, 2010). The dog is trained to resist a child's attempt to bolt, giving the caregiver time to intervene. Beyond increasing safety, there is also emerging evidence suggesting that assistance dogs for children with ASD can provide multisensory stimulation, enabling children to better regulate themselves to facilitate learning (Burrows et al., 2008).

Berry and colleagues (2013) completed a critical review of the use of therapy dogs for children with ASD concluding that such programs can benefit children's social behaviours. However, they emphasised the poor quality of research available at the time (Berry et al., 2013). A systematic review by O'Haire (2013) determined that research around animal assisted interventions for children with ASD was in an initial phase of proving the approach and that additional research using higher quality designs was essential. This review has therefore been undertaken to synthesise the current literature surrounding the efficacy of Autism assistance dog programs. Due to the emerging nature of the practice it is expected to build upon the findings from Berry et al.'s (2013) review where only six papers were found. It sought to focus specifically on assistance dogs and the improvements in quality of life arising from this animal assisted therapy, as indicated in the current literature. The research question underpinning this systematic review was thus: what effect does participating in an assistance dog program have on the quality of life of children with Autism Spectrum Disorders and their caregivers?

\section{Methods}

\section{Protocol and registration}

No protocol for this systematic review was conducted.

\section{Eligibility criteria}

Types of studies: Given the limited number of studies in this area, papers were not excluded due to their research design, publication date, or language. Inclusion of all study types maximised results, and provided a more thorough understanding of the current evidence surrounding assistance dog therapies for children with ASD.

Types of participants: Studies were included if they focused on children aged 0-18 years with a diagnosis of ASD, and/or their caregivers. Studies describing assistance dog programs delivered to children with other diagnoses were excluded. 
Types of interventions: Any interventions involving assistance dogs for children with ASD were included. Studies examining the impact of pet dogs on children with ASD were excluded.

Types of outcome measures: Various outcome measures were included if they pertained to quality of life. Quality of life is a broad concept and for the purpose of this review was considered to be any factor that positively impacts on the development, health and/or wellbeing of children with ASD and their caregivers. Examples include development of language skills, increased social interactions, decreased stress and/or increased participation in activities of daily living.

\section{Information sources}

Studies for this systematic review were sourced from online databases (see 'Search' section), with no date or language limitations. The final search of these databases was conducted on $25^{\text {th }}$ August 2016. In addition, the reference lists of sourced studies were reviewed for additional relevant studies.

\section{Search}

The following databases were searched using the keywords 'Autism Spectrum Disorder', 'assistance dogs', 'therapy dog', 'children', 'Autism', 'quality of life' and 'dogs':

- CINAHL Plus

- Cochrane Library

- Informit Health Collection

- Lippincott, Williams and Wilkins eJournals

- SAGE Journals Online

- Medline

- Ovid

- Oxford Scholarship Online: Social Work

- ProQuest

Keywords were searched in all fields and combined with 'AND' as the Boolean phrase. No restrictions were placed on language or date of publication, however all searches were restricted to peer-reviewed studies only. A total of 1412 articles were retrieved through database searches. Six articles were retrieved through the secondary search of reviewing the reference lists of relevant articles.

\section{Selection criteria}

Inclusion criteria were:

- Studies that involved children with ASD and their caregivers,

- Studies involving assistance/therapy dogs,

- Studies focusing on quality of life outcomes of interventions.

Exclusion criteria were:

- Studies of children with disabilities other than ASD,

- Studies involving assistance animals other than dogs,

- Studies involving pet dogs,

- Studies that measured outcomes irrelevant to quality of life.

\section{Data collection process}

One reviewer extracted data from each of the ten studies, with assistance from a supervisor. Data was recorded using applicable aspects of the EPOC Data Collection Form (EPOC, 2013), and a self-developed data extraction table using specific data items (outlined below) was used. Meta-analysis was not possible with the retrieved studies, due to the vastly differing study designs and outcome measures used in each paper. 


\section{Data items}

Data extracted from the ten studies included study design, participant information (age, gender, number of participants), type of intervention, variables, outcome measures, key findings and any other distinguishing factors.

\section{Risk of bias in individual studies}

The risk of bias in each study was reviewed using the EPOC Data Collection Form (EPOC, 2013). This included looking at study designs, recruitment of participants, allocation of interventions and recording of outcomes. Studies were classified as high, moderate or low quality based on the outcome of the EPOC data collection form process.

\section{Summary measures}

The included studies varied in qualitative and quantitative design, so summarising through analysing data was not possible. Due to the varying nature of included studies, results were summarised by grouping similar findings into themes, and drawing over-arching conclusions from these.

\section{Synthesis of results}

Data retrieved from each study was compared to determine similarities and differences. Due to the varying design and focus of each study, it was not possible to combine data, however an overall conclusion of the effect of Autism assistance dog programs on quality of life was informed by comparing the outcomes of the studies.

\section{Risk of bias across studies}

In order to reduce the risk of bias when analysing data from the included studies, the completeness of the data was reviewed. This involved reviewing studies' methods to reported results. In addition, studies' protocols were reviewed where possible.

\section{Results}

\section{Study selection}

Initially, duplicates were removed ( $n=593$ ), and the titles and (if necessary) abstracts of retrieved studies were reviewed to see if they met the exclusion and inclusion criteria (771 excluded).

After this initial screen, the remaining studies $(n=54)$ were examined in full to reassess their suitability against the exclusion and inclusion criteria more thoroughly (39 excluded). Examples of articles excluded at this stage include Wright et al. (2015), who examined the effect of pet dogs in families with children with Autism; and Butterly, Percy, \& Ward (2013) who reviewed outcome measures used in Autism assistance dog programs. After the study selection process, ten studies were included in the systematic review (see Figure 1). 


\section{Figure 1: Study selection process}

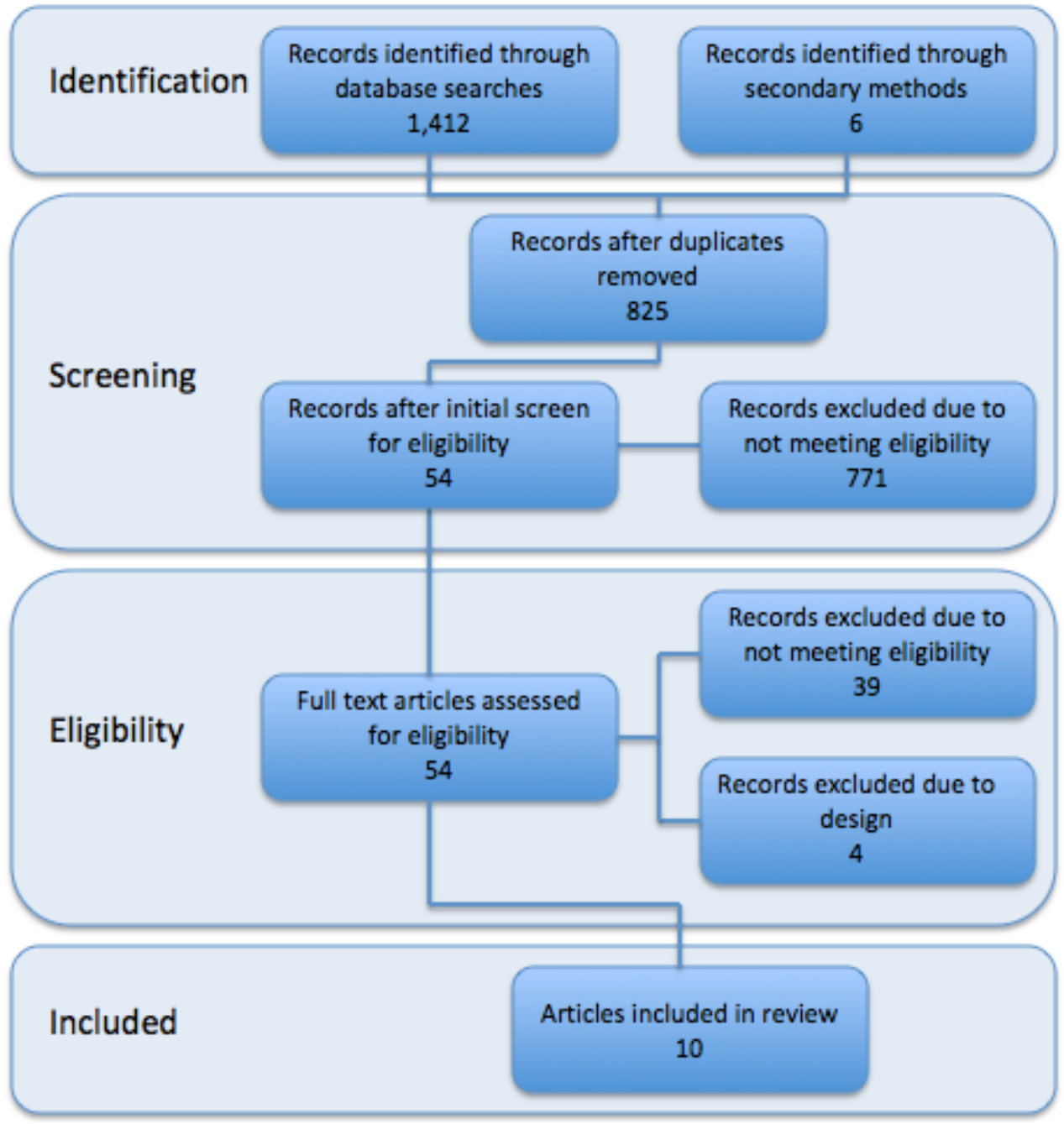

\section{Study Characteristics}

Six of the included studies used a qualitative design (see Alison, 2010; Burgoyne, Dowling, Fitzgerald, Connolly, Browne, \& Perry, 2014; Burrows et al., 2008; Fung, 2015; Smyth \& Slevin, 2010; Solomon, 2010), three used a quantitative design (see Funahashi, Gruebler, Aoki, Kadone, \& Suzuki, 2014; Silva, Correia, Lima, Magalhaes, \& Sousa, 2011; Viau et al., 2010) and one used a mixed-methods design (see Wild, 2012). The publication dates of the included studies ranged from 2008 to 2015. Sample sizes of included studies varied from one to 221, with the majority of studies having fewer than ten participants (see Burgoyne et al., 2014; Viau et al., 2010; Wild, 2012). All studies focused on children with ASD, and their caregivers. Six studies focused purely on the children (see Alison, 2010; Funahashi et al., 2014; Fung, 2015; Silva et al., 2011; Solomon, 2010; Viau et al., 2010), and four studies included parents as the primary participants (see Burgoyne et al., 2014; Burrows et al., 2008; Smyth \& Slevin, 2010; Wild, 2012).

Although all studies focused on the effects of introducing an assistance dog to children with ASD, in different settings, the nature of interventions varied. Half of the studies reviewed the experiences of families who engaged in formal Autism assistance dog programs (see Burgoyne et al., 2014; Burrows et al., 2008; Smyth \& Slevin, 2010; Viau et al., 2010; Wild, 2012), and the remaining studies used more clinical designs, introducing assistance dogs to children with ASD during controlled therapy sessions (see Alison, 2010; Funahashi et al., 
2014; Fung, 2015; Silva et al., 2011; Solomon, 2010). The studies also varied in the way data was collected, including videotaping sessions and observing the children's behaviours (see Alison, 2010; Burrows et al., 2008; Funahashi et al., 2014; Fung, 2015; Silva et al., 2011; Solomon, 2010), parent questionnaires of the benefits of the assistance dogs (see Alison, 2010; Burgoyne et al., 2014; Burrows et al., 2008; Smyth \& Slevin, 2010; Solomon, 2010; Wild, 2012), and measuring cortisol levels of children prior to, during and after participating in Autism assistant dog programs (see Viau et al., 2010). Most studies used a combination of data collection methods.

\section{Risk of bias within studies}

Using the review method outlined above, all the studies included in this review were rated as having low quality design, confirming the conclusions of previous reviews by O'Haire (2013) and Berry et al. (2013), and introducing a high risk of bias. In the studies, no participants were selected randomly; most were selected through pre-existing Autism assistance dog programs, or waitlists for these programs (Burgoyne et al., 2014; Burrows et al., 2008; Smyth \& Slevin, 2010; Viau et al., 2010; Wild, 2012). Participants were not randomly assigned an intervention in any of the studies, nor were any blind assessors utilised, although multiple studies did include a control group of either a typically developing child subjected to the same intervention as the child with ASD (Funahashi et al., 2014), or families with children with ASD not participating in an Autism assistance dog program (Burgoyne et al., 2014). In addition, the limited sample size evident in the majority of studies presents some challenges in generalising the findings across target populations. Therefore, the respective limitations and biases in the research are acknowledged in the discussion of their implications. However, it should be noted that the assessment of the risk of bias across studies was particularly difficult due to the varying study designs and results. Additionally, due to the articles being assessed by one reviewer, it is recognised that there is a risk of bias being present in the data collected and interpreted.

Nevertheless, the inclusion of additional studies in this review, since those reviews completed by O'Haire (2013) and Berry et al. (2013), adds to our knowledge of the field. Included studies provide useful findings and were reported well. For example, no inconsistencies between the methods and reported results within studies were found. In addition, similar themes emerged from most studies, indicating accuracy of results.

\section{Results of individual studies}

All studies indicated there were positive benefits arising from Autism assistant dog programs. Two also reported some indifferent or negative effects, however. Table 1 outlines the key findings from each study: 


\section{Table 1: Included studies}

\begin{tabular}{|c|c|c|c|}
\hline $\begin{array}{l}\text { Citation \& Country of } \\
\text { Study }\end{array}$ & Sample & $\begin{array}{l}\text { Methodology - } \\
\text { Data Collection/Data analysis }\end{array}$ & Outcomes \\
\hline Alison, C. (2010) - US & $\begin{array}{l}\mathrm{N}=3 \text {; one } 9 \text { year old boy and } \\
\text { siblings, one male aged } 7 \text { and one } \\
\text { female aged } 10 .\end{array}$ & $\begin{array}{l}\text { Qualitatively through observation of behaviours as } \\
\text { informed by the DSM IV. Positive behaviours included } \\
\text { social behaviour and social communication. Negative } \\
\text { behaviours included non-social behaviour, self- } \\
\text { stimulatory behaviour and non-social communication. } \\
\text { Quantitative parental report scale on social } \\
\text { responsiveness also used. }\end{array}$ & $\begin{array}{l}\text { Social behaviours increased in the presence of the } \\
\text { assistance dog. }\end{array}$ \\
\hline $\begin{array}{l}\text { Burgoyne, L et al. } \\
(2014) \text { - Ireland }\end{array}$ & $\begin{array}{l}\mathrm{N}=134 \text { parents/guardians with an } \\
\text { assistant dog and } 87 \text { on the wait- } \\
\text { list returned the postal survey; a } \\
\text { response rate of } 65 \% \text { and } 81 \% \\
\text { respectively. Participants' children } \\
\text { were around } 90 \% \text { male and all fell } \\
\text { under } 10 \text { years of age. The } \\
\text { majority of the experimental group } \\
\text { were } 7-9 \text { and control group } \\
\text { majority were below } 7\end{array}$ & $\begin{array}{l}\text { Quantitative scales were used to measure care-giver } \\
\text { strain, self-determination, perceptions of child safety } \\
\text { and public acceptance. Qualitatively, an open-ended } \\
\text { question was asked regarding benefits/constraints of } \\
\text { assistant dogs. } \\
\text { The survey was administered over post. } \\
\text { Qualitative data was analysed using a thematic } \\
\text { approach and was completed by two authors. }\end{array}$ & $\begin{array}{l}\text { Parents rated their children with ASD as significantly } \\
\text { safer from environmental dangers. } \\
\text { Parents perceived that the public acted more } \\
\text { respectfully towards their child. } \\
\text { Parents felt more competent managing their child. } \\
\text { Families had a greater sense of freedom. }\end{array}$ \\
\hline $\begin{array}{l}\text { Burrows, K et al. } \\
\text { (2008) - Canada }\end{array}$ & $\begin{array}{l}\mathrm{N}=10 \text { families ( } 7 \text { boys). Children } \\
\text { with ASD had an age range from } \\
4.5-14 \text { years old. Parents } \\
\text { interviewed were also main dog } \\
\text { handlers ( } 9 \text { mothers and } 1 \text { father })\end{array}$ & $\begin{array}{l}\text { Interviews with a parent and researcher observations. } \\
\text { Observations took place in a variety of settings. } \\
\text { Content analysis was employed to analyse } \\
\text { behaviours. For interviews, themes were identified } \\
\text { throughout the study which informed later interviews. } \\
\text { Data analysis ended once no new themes emerged } \\
\text { (analytic saturation). }\end{array}$ & $\begin{array}{l}\text { Therapy dogs increased the safety of children with } \\
\text { ASD in public. } \\
\text { Families gained freedom to participate in more public } \\
\text { outings and activities through increased safety. } \\
\text { Families perceived an increase in social recognition } \\
\text { and status in public. }\end{array}$ \\
\hline $\begin{array}{l}\text { Funahashi, A et al. } \\
(2014) \text { - Japan }\end{array}$ & $\begin{array}{l}\text { Case study of } 10 \text { year old boy with } \\
\text { ASD and a } 10 \text { year old boy with no } \\
\text { diagnoses or known difficulties. } \\
\text { Both took part in dog therapy for } \\
\text { the duration of the experiment ( } 7 \\
\text { months). }\end{array}$ & $\begin{array}{l}\text { A wearable interface device was used with both boys } \\
\text { for } 30-40 \text { minute session for } 7 \text { months to detect } \\
\text { smiles, positive social behaviours and negative social } \\
\text { behaviours. }\end{array}$ & $\begin{array}{l}\text { For both boys, positive social behaviours increased } \\
\text { when smiles increased. For the ASD boy negative } \\
\text { social behaviours decreased when smiles increased. } \\
\text { Positive behaviours generally increased throughout } \\
\text { sessions. } \\
\text { Negative behaviour decreased throughout sessions. } \\
\text { Quality of social interactions improved throughout } \\
\text { intervention. }\end{array}$ \\
\hline $\begin{array}{l}\text { Fung, S. (2015) -Hong } \\
\text { Kong }\end{array}$ & Case study of a 7 year old boy & $\begin{array}{l}\text { Social behaviours were measured at baseline, during } \\
\text { treatment, post-treatment and } 1 \text { month follow-up } \\
\text { through observation of videos. These were classed as }\end{array}$ & $\begin{array}{l}\text { Social communication increased during intervention } \\
\text { involving assistance dogs and remained higher than } \\
\text { baseline at follow-up. }\end{array}$ \\
\hline
\end{tabular}




\begin{tabular}{|c|c|c|c|}
\hline & & $\begin{array}{l}\text { social (verbal or nonverbal) or non-social and within } \\
\text { these two categories a variety of target behaviours } \\
\text { were coded. }\end{array}$ & \\
\hline $\begin{array}{l}\text { Silva, K et al. (2011) - } \\
\text { Portugal }\end{array}$ & $\begin{array}{l}\text { Case study of a } 12 \text { year old boy } \\
\text { exposed to two conditions: } 1 \text { ) his } \\
\text { therapist with a therapy dog and 2) } \\
\text { his therapist without }\end{array}$ & $\begin{array}{l}\text { Therapy sessions in both conditions were video- } \\
\text { recorded. Behaviour of the child in } 15 \text { random } 15 \\
\text { minute slots was analysed and quantitative analysis } \\
\text { was carried out on presence of these behaviours. }\end{array}$ & $\begin{array}{l}\text { Negative behaviours reduced in presence of the } \\
\text { therapy dog, including lower self-absorbed behaviours } \\
\text { and higher child-therapist engagement. }\end{array}$ \\
\hline $\begin{array}{l}\text { Smyth, C. \& Slevin, E. } \\
(2010) \text { - Ireland }\end{array}$ & $\begin{array}{l}\mathrm{N}=7 \text { parents of children with ASD } \\
(5 \text { mothers and two fathers). Age } \\
\text { range of child was } 5-12 \text { years old }\end{array}$ & $\begin{array}{l}\text { Interviews following an assistant dog program } \\
\text { Phenomenological approach employed }\end{array}$ & $\begin{array}{l}\text { Parents reported children's behaviour was more } \\
\text { manageable with less meltdowns. } \\
\text { Improved safety in public, with bolting behaviours } \\
\text { reducing or ceasing. } \\
\text { Reduced parental stress and reduced strain on family } \\
\text { unit. } \\
\text { Improvements in child's motor skills and } \\
\text { communication. } \\
\text { Increased family socialisation and confidence in } \\
\text { public. } \\
\text { Negative aspects included care of dog and parental } \\
\text { fear of children approaching other (potentially } \\
\text { dangerous) dogs. }\end{array}$ \\
\hline $\begin{array}{l}\text { Solomon, O. (2010) - } \\
\text { US }\end{array}$ & $\begin{array}{l}\text { Two case studies. One } 9 \text { year old } \\
\text { girl and one } 13 \text { year old boy. }\end{array}$ & $\begin{array}{l}\text { Transcripts from therapy dog sessions. Interviews with } \\
\text { parents. }\end{array}$ & $\begin{array}{l}\text { Therapy dogs helped children reorganise interactional } \\
\text { habits. } \\
\text { Enabled better adaptability. } \\
\text { Facilitated emotional connection between dog and } \\
\text { child and child and caregiver. }\end{array}$ \\
\hline $\begin{array}{l}\text { Viau, R et al. (2010) - } \\
\text { Canada }\end{array}$ & $\begin{array}{l}\mathrm{N}=42 \text { children with } \mathrm{ASD} \text { and their } \\
\text { families ( } 37 \text { boys). } 7.1 \pm 3.1 \text { years } \\
\text { old }\end{array}$ & $\begin{array}{l}\text { Semi-quantitative open-ended questionnaire for } \\
\text { parents } \\
\text { Salivary cortisol samples of children } \\
\text { Data collected in a period two-weeks prior to assistant } \\
\text { dog service. Throughout the four week service and } \\
\text { two weeks following }\end{array}$ & $\begin{array}{l}\text { Cortisol levels in children with ASD were lower in the } \\
\text { presence of the Autism assistance dog. } \\
\text { Problematic behaviours decreased during service } \\
\text { period; a change that continued during follow-up } \\
\text { period }\end{array}$ \\
\hline Wild, D. (2012) - US & $\begin{array}{l}\mathrm{N}=20 ; 10 \text { experimental group and } \\
10 \text { control. } \\
\text { Age range } 4-16 \\
\text { Families who have children with } \\
\text { ASD }\end{array}$ & $\begin{array}{l}\text { Quantitative and qualitative data taken. } \\
\text { Online, mail or telephone reporting of questionnaires } \\
\text { and surveys and interviews. Data collected } 3 \text { times } \\
\text { over a } 12 \text { month period at } 6 \text { month intervals }\end{array}$ & $\begin{array}{l}\text { Qualitative findings of increased child safety, however } \\
\text { no significant difference in child safety found in } \\
\text { quantitative data. } \\
\text { Social reciprocity increased. } \\
\text { Self-reported parental stress decreased. } \\
\text { No significant difference was found in parental stress } \\
\text { through quantitative measures. } \\
\text { No significant difference was found in quantitative } \\
\text { measurement of child's positive or negative } \\
\text { behaviours. }\end{array}$ \\
\hline
\end{tabular}




\section{Synthesis of results}

The main themes identified in the results of the studies included lower familial stress and increased parental/carer confidence in public space; changes in positive and negative behaviour in children with ASD; and improvements in communication, social development and motor skills for children in ASD when participating in assistance dog programs. In particular, families who participate in Autism assistance dog programs self-report experiencing less stress and having more confidence when in public due to the increase in safety provided by the dog. Also, children with ASD mostly exhibit greater positive behaviours and fewer negative behaviours when interacting with assistance dogs (however this finding was not universal across all studies)

Smyth \& Slevin (2010) also found that there were negative aspects to participating in an Autism assistance dog program, which included the responsibility of caring for the dog, and parental concern of their child approaching other (potentially dangerous) dogs. In addition, Wild (2012) reported differences between qualitative and quantitative findings. For example, when measured qualitatively, parental stress reduced, however no significant difference was found when parental stress was measured quantitatively.

\section{Discussion}

This review aimed to assess the current state of knowledge of the use of assistant dogs for children with ASD. Specifically, it aimed to assess studies looking at aspects of quality of life in children with ASD and their families. Quality of life was found to increase through three main themes: lower familial stress and increased parental/carer confidence in public space; changes in positive and negative behaviour in children with ASD; and improvements in communication, social development and motor skills for children in ASD.

A key finding of this review was that families engaging in an Autism assistance dog program experience less stress, and have more confidence when in public than those who do not (Burgoyne et al., 2014; Burrows et al., 2008; Smyth \& Slevin, 2010; Wild, 2012). Reduced familial stress is a valuable outcome considering research suggests that families with children with ASD experience higher stress than families with typically developing children, or children with other non-developmental disabilities (Dunn et al., 2001). This stress can impact on the parent and families' health and wellbeing, and limit access to and effectiveness of traditional intervention methods (Wright et al., 2015). Additionally, the finding of greater confidence in public suggests valuable effects of assistant dog programs in Autism, as multiple studies found that families with children with Autism rarely left the house as a family, due to the unpredictable, challenging and risky behaviours of the child with ASD (Burgoyne et al., 2014; Burrows et al., 2008; Smyth \& Slevin, 2010).

As already noted, a prominent challenging behaviour that many children with ASD exhibit is bolting, or absconding (Burgoyne et al., 2014; Burrows et al., 2008). Such behaviours can put the child at higher risk in public due to the child's reduced insight into potential dangers such as traffic (Wild, 2012). In extreme cases, chronic bolting can become unmanageable for parents, especially as their children grow, and in some cases can result in children having to be placed in residential facilities away from their parents (Burgoyne et al., 2014). Few interventions for children with ASD address personal safety (Wild, 2012). However, the findings of this review suggest that formal Autism assistance dog programs can make a remarkable change to bolting behaviours (Burgoyne et al., 2014; Burrows et al., 2008; Smyth \& Slevin, 2010; Wild, 2012). These findings were most prominent in the studies reviewing formal Autism assistance dog programs, as opposed to therapy dogs, where the child and the dog walk together, via a belt attachment (Burgoyne et al., 2014; Burrows et al., 2008; Smyth \& Slevin, 2010; Wild, 2012). Burgoyne et al. (2014), found that parents self-reported a greater sense of competence managing their child's behaviour in public, when with the assistance 
dog. Parents experienced a greater sense of freedom with an assistance dog, highlighting the dog's ability to facilitate 'normal' family outings, such as to the supermarket (Burgoyne et al., 2014). Burrows et al. (2008) reported that family outings were eased by the presence of the dog, with the child becoming more compliant and exhibiting less challenging behaviours than when in public without the dog. Smyth \& Slevin (2010) found that parents' concern for their child's safety reduced when walking with the assistance dog, as the dog would prevent their child's attempts to bolt, and stop at environmental hazards such as kerbs. In contrast, although Wild (2012) found qualitative data from parental reports suggested an immediate increase in child safety, quantitative data collected found no statistical significance in child safety between the experimental and control group. Data collected by Burgoyne and colleagues (2014), Burrows and colleagues (2008), and Smyth \& Slevin (2010), was all of a qualitative nature. This suggests that although qualitative data (mostly parental reports) shows a significant increase in child safety, and reduction in parental stress, this is yet to be reported in quantitative studies.

Six of the ten studies included found that children exhibit more positive behaviours and less negative behaviour when interacting with assistance dogs (Alison, 2010; Funahashi et al., 2014; Fung, 2015; Silva et al., 2011; Smyth \& Slevin, 2010; Solomon, 2010). This result was across various interventions, including formal assistance dog programs, and interventions involving controlled therapy sessions with assistance dogs. Qualitative data strongly supported the reduction in negative behaviours and increase in positive behaviours (Smyth \& Slevin, 2010; Solomon, 2010; Wild, 2012). However, quantitative data varied. Wild (2012) found no statistical significance in quantitative findings of children's positive adaptive behaviours. Other studies using quantitative designs found participants exhibited more frequent positive behaviours, and less frequent negative behaviours when interacting with assistance dogs (Alison, 2010; Funahashi et al., 2014; Fung, 2015; Silva et al., 2011). Positive behaviours included watching and patting the dog and increased communication with the dog and others (Funahashi et al., 2014). Negative behaviours included escaping, anxiety and anger (Funahashi et al., 2014). Therefore, although parental reports, and other qualitative findings, suggest children with ASD exhibit more positive behaviours and less negative behaviours when participating in assistance dog programs, the quantitative data is varied and cannot fully corroborate this finding.

Coupled with this increased confidence managing their child in public, was a reduced sense of self-consciousness about their child (Burgoyne et al., 2014; Burrows et al., 2008; Wild, 2012). Parents reported a sense of being judged by members of the public, due to their child's unpredictable unsociable behaviours (Burgoyne et al., 2014; Burrows et al., 2008). These feelings were found to reduce in the presence of the Autism assistance dog, as the dog increased the awareness to the public of the child's disability, and facilitated social inclusion of the family into their community.

The last key theme from the review was that children with ASD who participate in assistance dog programs experience improvements in their communication, social and motor development (Alison, 2010; Funahashi et al., 2014; Fung, 2015; Smyth \& Slevin, 2010; Solomon, 2010). This result was also consistent across the various interventions included. Smyth \& Slevin (2010), who studied the effects of participating in a formal assistance dog program, found that parents reported the dog helped facilitate motor skills, such as walking, throwing a ball, patting and grooming the dog. Parents also reported increases in communication, with the children attempting to communicate with the dog (Smyth \& Slevin, 2010). Funahashi et al. (2013) used a more controlled study design, comparing the behaviours of a child with ASD to that of their typically developing peer in controlled sessions with assistance dogs. They found the child with ASD increased social behaviours such as eye contact and communication with their mother as the intervention continued. Fung (2015) also found an increase in communication after intervention with an assistance dog, and reported this improvement remained higher at follow up, after the intervention had ceased. Through 
qualitative data, Solomon (2010) suggests that assistance dogs can act as an emotional connector between children with ASD and their caregivers, increasing the social interactions between these parties. Lastly, Alison (2010) reported a wide variety of developmental benefits from participating in assistance dog programs, including increasing in motor skills such as patting and cuddling, and social/communication skills such as eye contact and cooperative interactions. Alison (2010) asserted that the dogs acted as transitional objects increasing the child's interaction with the experimenter. Therefore, although Alison (2010) did not report on motor skills being transferred into other aspects of life, it is suggested that the use of an assistance dog in therapy sessions may allow for more functional and complex motor skills to be addressed than could be possible without the presence of the assistance dog.

Much of the data found through the included studies was from parent report or assessor observation of the child's behaviours. As suggested by Viau et al. (2010) and Funahashi et al. (2014), gathering data from the child's perspective is difficult due to the limited communication skills of most of the participants, and therefore they presented unique studies that aimed to overcome this challenge. Viau et al. (2010) studied the cortisol (stress hormone) levels of children with ASD prior to, during, and after participating in an Autism assistance dog program. They found that participants experienced a significant decrease in cortisol levels when the assistance dog was present, and that this remained lower than base line after a short period after the dog's removal (Viau et al., 2010). They suggest that this finding may support qualitative findings of reduced challenging behaviours in children with ASD when participating in assistance dog programs (Viau et al., 2010). Similarly, Funahashi et al. (2014) used smile detecting technology to quantitatively measure the happiness of a child with ASD when participating in therapy sessions with an assistance dog. They found an overall increase in positive behaviours when interacting with the assistance dog (Funahashi et al., 2014). As these studies both had small sample sizes, additional similar studies with larger sample sizes would assist to increase the validity of these findings; however the difficulty of sourcing large samples for studies such as this is acknowledged.

Regardless of limitations in methodology, findings do indicate Autism assistant dog programs can improve quality of life in children with ASD and their families. Future research may be able to address difficulties with research design. For example, in absence of large sample sizes future studies may use mixed-methods designs to enable a comprehensive exploration of the issues and definitively measure their impact and longer-term effects.

\section{Strengths and Limitations}

This review of the literature involved a search of a large number of databases, ensuring a range of studies were identified. This was evidenced through the high number of duplicate articles being found across databases, with few new articles being found on completion of the search. However, there are also key limitations that need to be acknowledged. Most notable is the higher risk of bias and/or error in the selection of studies and analysis of data due to this process being completed by one reviewer, and it is acknowledged that it is best practice to use a team of reviewers to reduce bias and user error. Furthermore it is also recognised that the results generated reflect the quality of the search terms used and more variations with search terms, for example 'autistic' and 'canine', may have identified some different results.

\section{Conclusion}

The purpose of this review was to collate the current available evidence on assistance dog programs for children with ASD in order to better understand such program's effect on the quality of life of these children, and their caregivers. Ten articles were found to meet the inclusion and exclusion criteria, and were included in the review. Overall, the data collated in this review has suggested that the quality of life of children with ASD and their caregivers is 
likely to be enhanced through participating in assistance dog programs. Key findings indicated an improvement in child and caregiver quality of life is achieved through the mechanisms of improvements in safety, resulting in decreased caregiver stress, as well as facilitation of motor, social and communication development in the child, and a decrease in negative behaviours. However, these findings were mostly from qualitative measures, and not always supported by quantitative data. For instance, Wild (2012) found no significant difference in child behaviours, safety or parental stress when data was collected through quantitative methods. This highlights the need for further research using higher quality designs in order to gather more reliable data on the efficacy of assistance dog programs to influence policy makers and decision makers. This paper has allowed for emerging evidence to be reviewed with the result being new evidence supporting that of previous studies and reviews. As the use of therapy dogs continues to increase in popularity, it is vital to continue to review the efficacy of these programs, to ensure the best outcomes to the quality of life of children with ASD and their caregivers. 


\section{References}

Alison, C. (2010). Using Dogs in a Home-based Intervention with Children with Autism Spectrum Disorders. (Doctor of Philosophy), Texam A\&M University, Texas.

American Psychiatric Association. (2013). Diagnostic and Statistical Manual of Mental Health Disorders. Retrieved from

http://dsm.psychiatryonline.org.libraryproxy.griffith.edu.au/doi/full/10.1176/appi.books $.9780890425596 . d s m 01$

Australian Bureau of Statistics (ABS) (2012). 'Autism in Australia.'

Retrieved from http://www.abs.gov.au/ausstats/abs@.nsf/Latestproducts/4428.0Main Features32012? opendocument $\&$ tabname $=$ Summary $\&$ prodno $=4428.0 \&$ issue $=2012 \&$ num $=\&$ view $=$

Berry, A., Borgi, M., Francia, N., Alleva, E., \& Cirulli, F. (2013). 'Use of Assistance and Therapy Dogs for Children with Autism Spectrum Disorders: A Critical Review of the Current Evidence', The Journal of Alternative and Complementary Medicine, 19 (2): 73-80.

Burgoyne, L., Dowling, L., Fitzgerald, A., Connolly, M., Browne, J., \& Perry, I. (2014). 'Parents' Perspectives on the Value of Assistance Dogs for Children with Autism Spectrum Disorder: A Cross-sectional Study', BMJ Open, 4.

Burrows, K., Adams, C., \& Spiers, J. (2008). 'Sentinels of Safety: Service Dogs Ensure Safety and Enhance Freedom and Well-Being for Families with Autistic Children', Qualitative Health Research, 18 (12): 1632-1649.

Butterly, F., Percy, C. \& Ward, G. (2013). 'Brief Report: Do Service Dog Providers Placing Dogs with Children with Developmental Disabilities Use Outcome Measures and If So What Are They?', Journal of Autism \& Developmental Disability, 43: 2720-2725.

Dunn, M. E., Burbine, T., Bowers, C. A., \& Tantleff-Dunn, S. (2001). 'Moderators of stress in parents of children with autism', Community Mental Health Journal, 37: 39-52.

Effective Practice and Organisation of Care (EPOC). (2013). Data Collection Form. Retrieved from http://epoc.cochrane.org/epoc-specific-resources-review-authors

Funahashi, A., Gruebler, A., Aoki, T., Kadone, H., \& Suzuki, K. (2014). 'Brief Report: The Smiles of a Child with Autism Spectrum Disorder During Animal-assisted Activity May Facilitate Social Positive Behaviours - Qualitative Analysis with Smile-detecting Interface', Journal of Autism \& Developmental Disorders, 44: 685-693.

Fung, S. C. (2015). 'Increasing the Social Communication of a Boy With Autism Using Animalassisted Play Therapy: A Case Report', Advances, 29 (3): 27-31.

Hall, S., Wright, H., \& Mills, D. (2016). 'What Factors are Associated with Positive Effects of Dog Ownership in Families with Children with Autirm Spectrum Disorcer? The Development of the Lincoln Autism Pet Dog Impact Scale', PLoS ONE, 11 (2).

O'Haire, M. (2013). 'Animal-Assisted Intervention for Autism Spectrum Disorder: A Systematic Literature Review', Journal of Autism \& Developmental Disorders, 43 (7): 1606-1622.

Raising Children Network. (2016). 'Autism Spectrum Disorder (ASD): an overview'. Retrieved from: http://raisingchildren.net.au/articles/autism_spectrum_disorder_overview.html

Silva, K., Correia, R., Lima, M., Magalhaes, A., \& Sousa, L. d. (2011). 'Can Dogs Prime Autistic Children for Therapy? Evidence from a Single Case Study', The Journal of Alternative and Complementary Medicine, 17 (7): 655-659.

Smyth, C., \& Slevin, E. (2010). 'Experiences of Family Life with an Autism Assistance Dog', Learning Disability Practice, 13 (4).

Solomon, O. (2010). 'What a Dog Can Do: Children with Autism and Therapy Dogs in Social Interaction', ETHOS Journal of the Society for Psychological Anthropology, 38 (1): 143-166.

Viau, R., Arsenault-Lapierre, G., Fecteau, S., Champagne, N., Walker, C.-D., \& Lupien, S. (2010). 'Effect of Service Dogs on Salivary Cortisol Secretion in Autistic Children', Psychoneuroendocrinology, 35: 1187-1193.

Wild, D. (2012). The Impact of Canine Assistance for Children with Autism and the Family Unit. (Doctor of Education), Walden University. 
Wright, H., Hall, S., Hames, A., Hardiman, J., Mills, R., Team, P., \& Mills, D. (2015). 'Acquiring a Pet Dog Significantly Reduces Stress of Primary Carers for Children with Autism Spectrum Disorder: A Prospective Case Control Study', Journal of Autism \& Developmental Disorders, 45: 2531-2540. 


\section{Biographical Notes}

Esther Sprod is an occupational therapist from Adelaide, South Australia. She works with children with a range of developmental disabilities, specializing in children with vision impairment. Esther completed a Masters of Human Services majoring in Orientation and Mobility in 2016 and uses this knowledge to provide more holistic support to her clients and their families.

Michael Francis Norwood has completed a BSc (Hons) in Psychology and a Masters of Cognitive and Clinical Neuroscience. In the United Kingdom, he worked in several schools with children with learning and behavioural needs. Since moving to Australia he has worked in research for The Hopkins Centre and is a PhD candidate at Griffith University. 